\title{
IOT Based Stress Detection and Health Monitoring System
}

${ }^{1}$ A.Anusha, ${ }^{* 2}$ N. Padmaja, ${ }^{3}$ D.V.S Manaswi, ${ }^{4}$ B.Sathish Kumar

${ }^{1}$ Digital Electronics and Communication Systems, Sree Vidyanikethan Engineering College, Tirupati.

${ }^{2}$ Center for Communication and Signal Processing, Sree Vidyanikethan Engineering College, Tirupati.

${ }^{3,4} \mathrm{ECE}$, Sree Vidyanikethan Engineering College, Tirupati

Email:anushaadhisetty@gmail.com,padmaja202@gmail.com,dvsmanaswi1999@gmail.com satishkumarbodagala@gmail.com

Received: 06th December 2019, Accepted: 20th January 2020, Published: 30th April 2020

\begin{abstract}
The effects of stress are causing rigorous damage to the mental as well as physical state of humans. It is very difficult to identify whether a person is in stress. The person may look healthier physically but may not be in a state of good health due to the stress within the body. Their mental stability also gets affected and may further lead to chronic ailments due to persistent stress. However, it is very essential to monitor stress levels regularly which help in diagnosis of any abnormalities in the body that may lead to chronic illness in future. The Wireless networks based on IOT (Internet of Things) provides wide range of opportunities to monitor stress levels regularly and transmit the information to the concerned for immediate action. A model is designed and developed to detect the stress levels using various sensors such as heartbeat rate, blood pressure (BP), body temperature and concentration of $\mathrm{CO} 2$ gas. Further based on the values of these sensors, the levels of stress is calculated and the information is transmitted using IOT.
\end{abstract}

Keywords

Stress, IOT, Sensors, Monitoring System.

\section{Introduction}

Stress is a major concern in the modern society now a day. All are engaged in their works and almost all people including students, employees all are working restlessly to meet their deadlines, targets etc. Quite often, people are aware of being under heavy work pressure and mental stress levels, but neglect their state of health [2][4]. They also forget to have medicine at the right time and it may lead to fatal effects sometimes death also. Certain levels of sensors like heart beat level, blood pressure etc. can be alarming if left uncontrolled. When the right medicine is given at right time, it can help prevent heart attacks and reduce the probability of deaths. So design of stress detection and health monitoring technology that could help people to understand their state of mind and body is very essential [9]. In the recent years, wireless technology is playing a crucial role in various sectors as well as biomedical to provide better health care. Many devices are being developed for continuous monitoring [5]. In many of the existing systems, the data is recorded and stored in general storage server that is generally accessible to the staff and doctors only [10]. In the proposed system, a model is designed to monitor the heartbeat rate, blood pressure, temperature and humidity and respiration using various sensors which will be will be uploaded to the server through WIFI module. A message could be sent to concerned person or doctor through GSM module. The model consumes less power and is designed to detect the level of stress with good efficiency [11].

\section{Block Diagram}

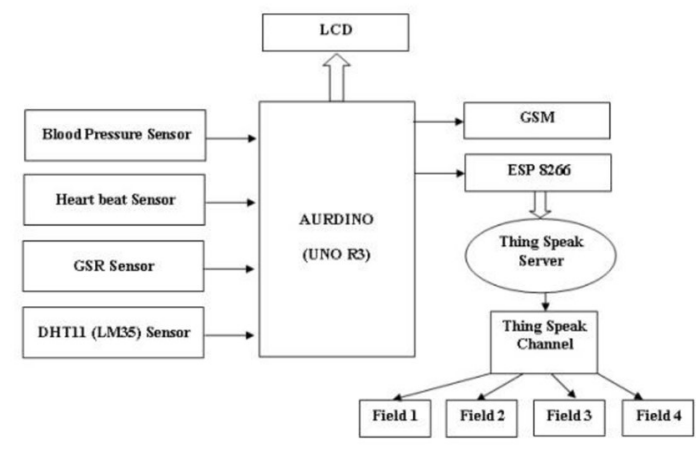

Fig 1: Block Diagram of the Proposed IOT Based Stress Detection System. 
Figure-1: Represents the block diagram of the proposed IOT based stress detection system that includes various sensors for detection of stress and the temperature, blood pressure, heart beat, gas values are sensed by the sensors where the data is processed and stored, whenever the microcontroller encounters any abnormal value of any parameter it alerts the person or Doctor by sending SMS to the mobile through GSM module [4].

\section{Hardware Description}

\section{Arduino}

The Arduino UNO is a microcontroller of ATmega328contains 14 pins. The Arduino board does not have capacity to execute code by itself accompanied by any external power supply. The Arduino board has inbuilt program whether it is working or not. The Arduino board has very easy compatible interface design for communicating accompanied by the sensors and it needs only $5 \mathrm{v}$ supply.

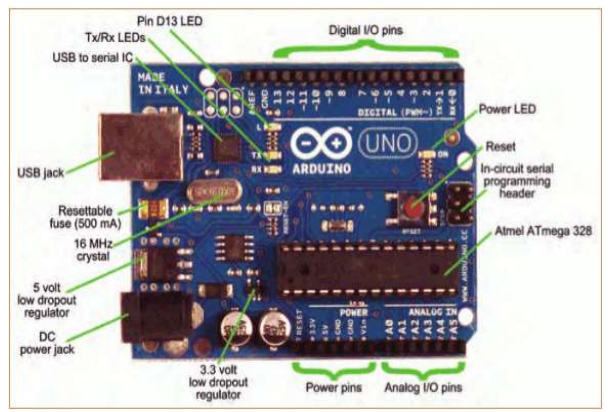

Fig 2: Arduino UNO R3

\section{Blood Pressure Sensor}

Blood pressure sensor (number) measures and displays the values of the Blood Pressure \& Pulse rate and it will send the measured values to other devices through serial communication. Display shows the readings of Systolic, Diastolic and Pulse Rate respectively. It resembles a wrist watch which eliminates pumping procedure.

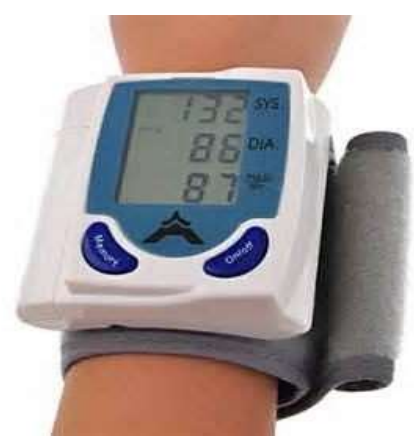

Fig 3: BP Sensor

\section{Features of the BP Sensor}

Smart automatic compression and decompression

60 memory groups for storing the value measurements

Power saving mode if it will sit idle for more than 3 minutes

Large display screen

Power specification: $+5 \mathrm{~V}$

Communicates with other devices serially.

Allows compression and decompression

\section{Specifications of the Blood Pressure Sensor}

It operates at $5 \mathrm{v}, 200 \mathrm{ma}$ voltage regulated and each reading consists of 15 bytes at 9000 baud rate. The output reading is 8 bit value in ASCII format fixed digits from 000 to 255 . 


\begin{tabular}{|l|c|c|}
\hline \multicolumn{1}{|c|}{ Name of the Stage } & Systolic (mm Hg) & Diastolic (mm Hg) \\
\hline Hypotension & $<90$ & $<60$ \\
\hline Desired & $90-119$ & $60-79$ \\
\hline Pre Hypertension & $120-139$ & $80-89$ \\
\hline Stage 1 Hypertension & $140-159$ & $90-99$ \\
\hline Stage 2 Hypertension & $160-179$ & $100-109$ \\
\hline Hypertensive Crisis & $\geq 180$ & $\geq 110$ \\
\hline
\end{tabular}

Table 1: Standard Classification Chart of Blood Pressure (Values) for Adults

\section{GSM (Global System for Mobile Communication)}

A GSM module has a RS32 interface for serial communication with an outside fringe. It regulates a simple transporter flag to encounter computerized info and demodulates to interpret the transparent data. GSM is an open and digital cellular technology for transmitting mobile voice and data services. A GSM digitalizes and reduces the data, then sends it down through a channel with two different streams of client data, each in it has own particular time slot.

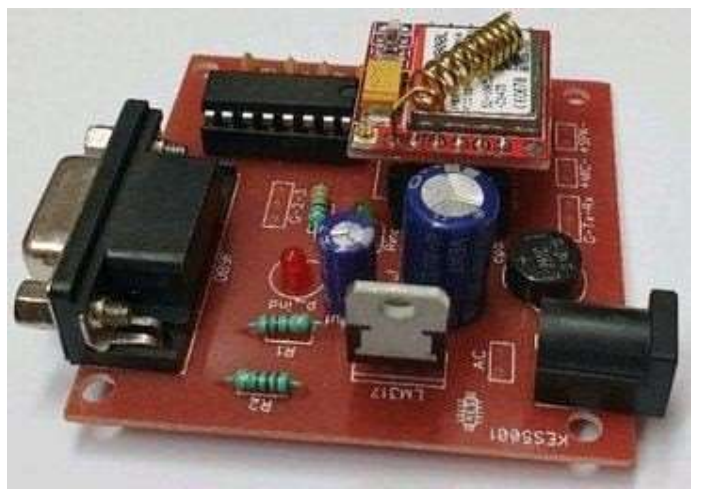

Fig 4: GSM Module

\section{DHT11 Temperature}

The DHT11 sensor is temperature and humidity sensor. It measures the temperature and humidity of the surroundings. This sensor can be interfaced with any microcontroller and has the provision to transmit the information to microcontroller. It can measure temperature ranging from $0^{\circ} \mathrm{C}$ to $50^{\circ} \mathrm{C}$ and humidity in range of $20 \%$ to $90 \%$ with an accuracy of $\pm 1{ }^{\circ} \mathrm{C}$ and $\pm 1 \%$.

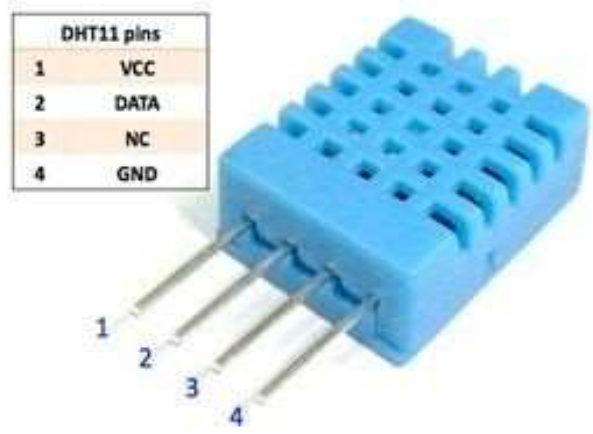

Fig 5: DHT11 (LM35) Sensor

\section{NodeMCU: ESP8266}

The ESP8266 is inbuilt Wi-Fi module incorporated in SOC with transfer control protocol and internet convention stack that can provide controller to access WI-FI. For the wireless communication ESP8266 WiFi module is used for sending the data from the Arduino to the thingspeak server. 


\section{Software Requirements}

Arduino Integrated Development Environment (IDE) software is used to program Aurduino that provides comprehensive facilities to computer programmers for software development. The language $\mathrm{C}$ is used to write the program and further uploaded to the Arduino.

\section{Methodology}

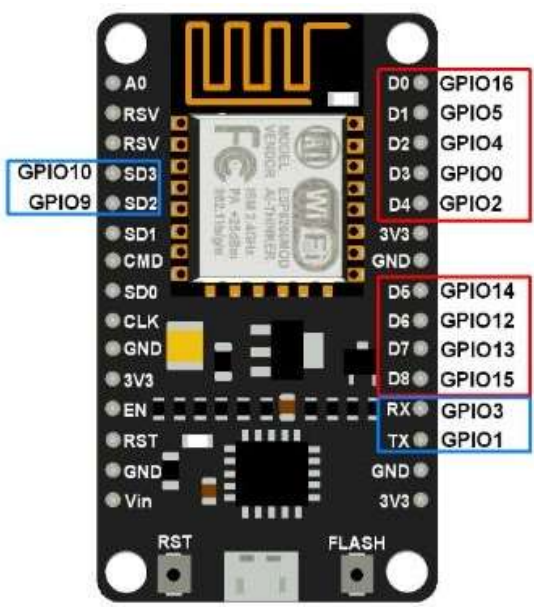

NodeMCU DevKit GPIOs

Fig 6: NodeMCU ESP8266

The temperature, blood pressure, heart beat, gas values are sensed by the sensors and the sensor values are sent to the microcontroller for further processing and storing. The values of the sensor outputs are compared with the predefined values indicated in Table 1. Whenever the microcontroller encounters the abnormal value of any parameter, it alerts the person by sending SMS to the mobile using the Wi-Fi module. Also these values are sent to the thingspeak server where the parameters get monitored continuously.

\section{Results}

The proposed model has been tested on different users with different age groups and the values are recorded and are uploaded to the thingspeak server by using wifi module and the message will be sent to the user through GSM module. The efficiency of the model is $96.10 \%$ compared to the values recorded by the physician. Figure- 7 . shows the setup of the hardware model of the stress detection system. Figure- 8 displays the Co2 value of Person- 1 using MQ2 sensor. Figure-9 displays the temperature values of Person1 in centigrade using DHT11 (LM35) Sensor. Figure-10 displays Systolic, Diastolic \& Pulse Rate of Person 1 using by BP sensor and Figure- 11 illustrates the heart rate of the person 1 which defines the user heart rate.

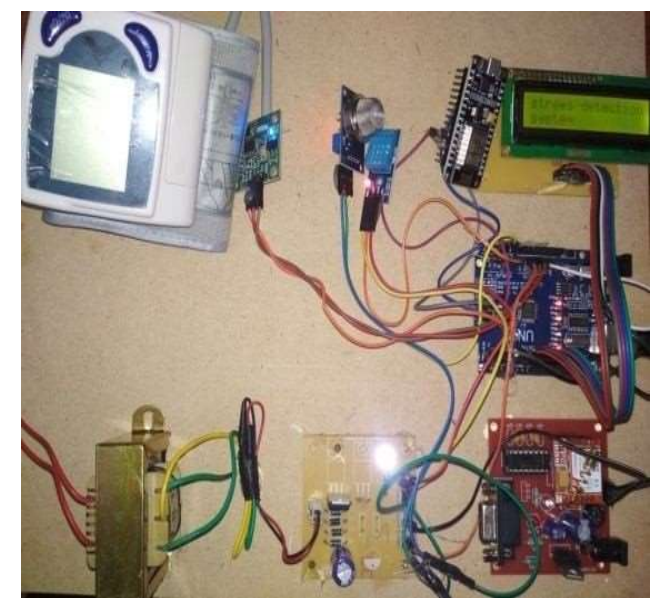

Fig 7: Hardware Setup of the Model 


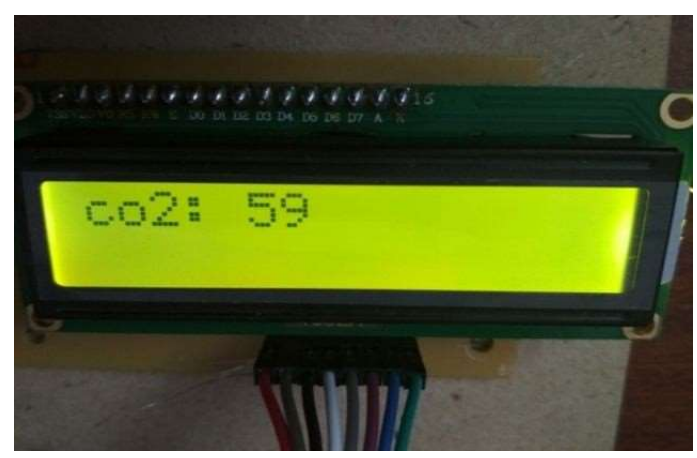

Fig 8: Displaying Co2 Value of Person-1 using MQ2 Sensor

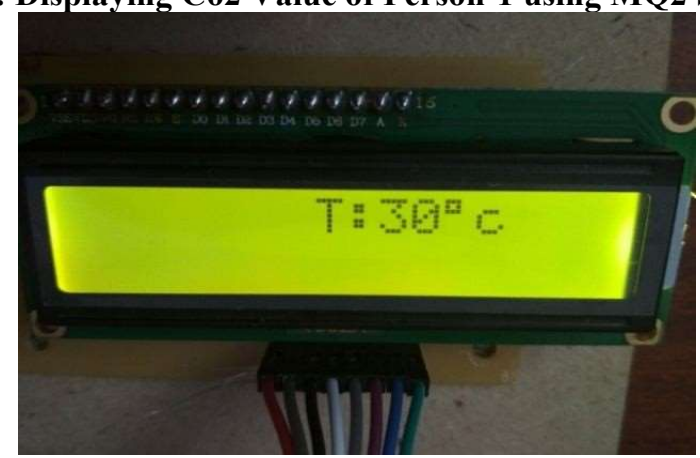

Fig 9: Displaying Temperature value of Person1

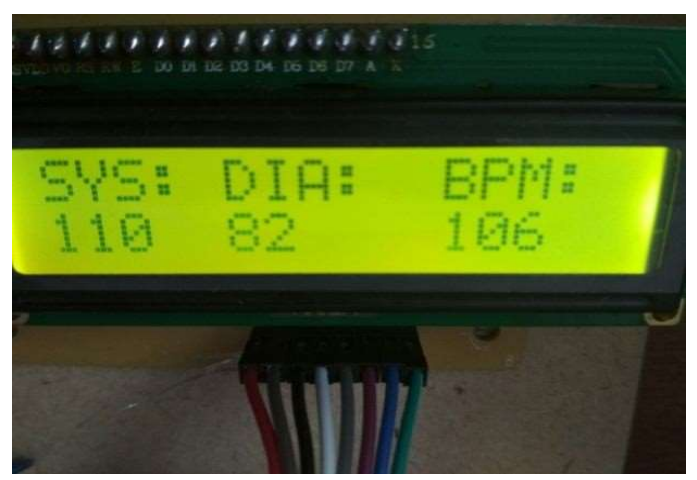

Fig 10: Displaying Systolic, Diastolic \& Pulse Rate of Person 1 using by BP Sensor

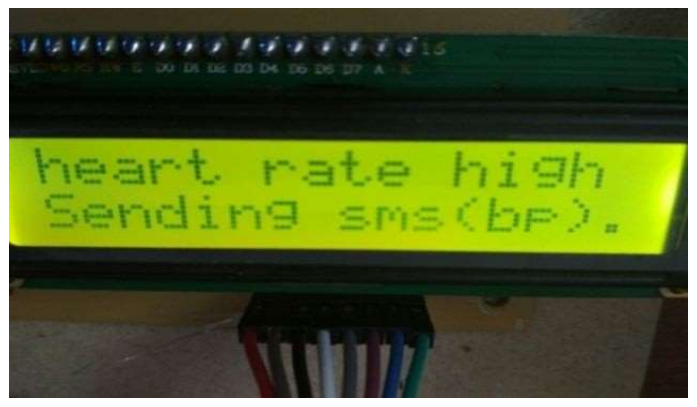

Fig 11: Displaying Heart Rate of Person 1 

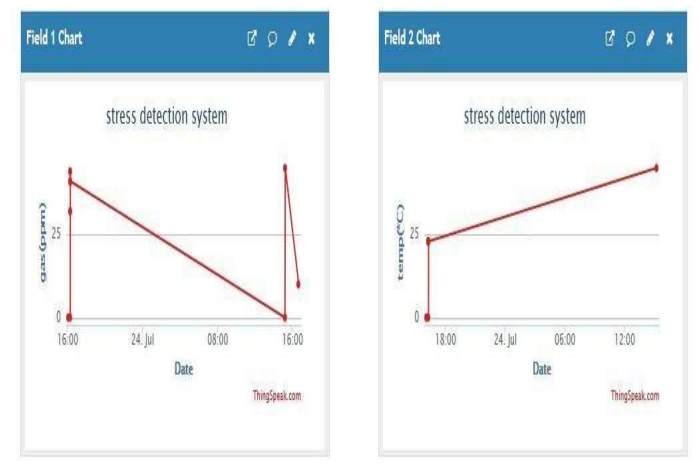

Fig12: MQ2 and Temperature Values Uploaded to Thingspeak

Figure-12 is the plot using thinkspeak that defines the gas and temperature values of person 1 indicating the user stress level is moderate. Figure-13 is the plot using thinkspeak that defines systolic, Diastolic and Pulse rate values of person 1 uploaded to thingspeak. Figure-14 displays the over all stess levels. The developed model has been tested on different persons of different age groups and has been tabulated in Table. 2 .
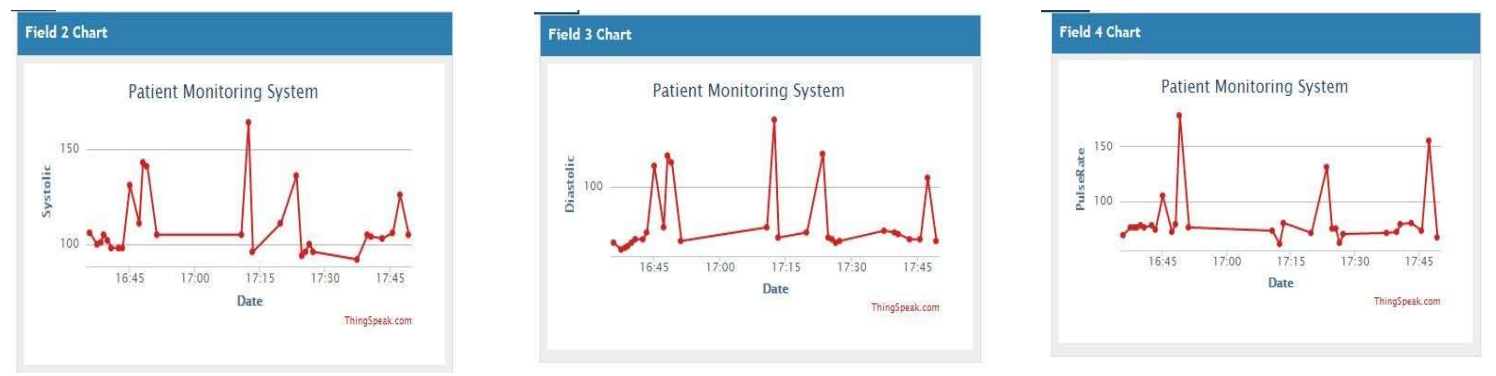

Fig 13: Systolic, Diastolic and Pulse Rate Values Uploaded to Thingspeak
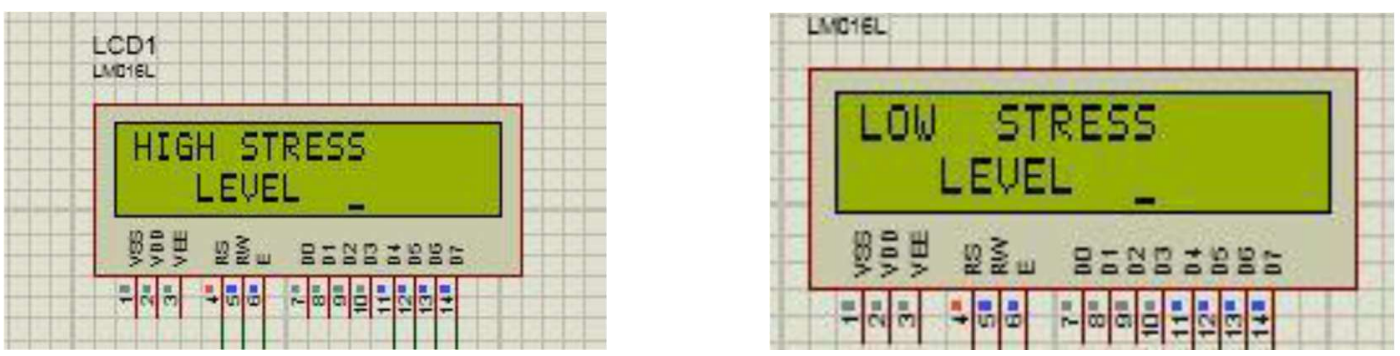

Fig 14: Display of High and Low Stress Levels

\begin{tabular}{|c|c|c|c|c|ll|}
\hline User No & Co2Gas (PPM) & Temp $\left({ }^{\mathbf{0}} \mathbf{C}\right)$ & Systolic & Diastolic & BPM & Result \\
\hline 1 & 50 & 42 & 160 & 110 & 92 & High Stress \\
\hline 2 & 47 & 40 & 140 & 95 & 90 & Moderate Stress Level \\
\hline 3 & 45 & 37 & 138 & 93 & 85 & Low Stress Level \\
\hline 4 & 38 & 35 & 125 & 85 & 72 & Normal Level \\
\hline
\end{tabular}

Table 2: Measured Values of Sensors for Different Persons

\section{Conclusion and Future Scope}

An IOT based stress detection system is designed and developed using Arduino. The system successfully and accurately detects the stress levels using various sensors such as heartbeat rate, blood pressure (BP), body temperature and concentration of $\mathrm{CO}_{2}$ gas. Based on the values of these sensors, the levels of stress is calculated and the information is transmitted using IOT to the concerned persons mobile for necessary action. The developed model is more flexible and consuming less power. It is very useful in medical camps and is very useful in taking 
care of disabled persons. This work can be extended by using GSR sensor, EEG sensor; Muscle sensor etc and this model can be built on a SOC device.

\section{References}

[1] Pei - Cheng Hii, Wan-Young Chung, "A Comprehensive Ubiquitous Healthcare Solution on an Android Mobile Device", Sensors 2011.

[2] Health Gare: "A Real-Time Wearable System for Monitoring and Analyzing Physiological Signal" Nuria Oliver 1 Fernando 2008.

[3] Iman, Auburn University, "Tensor Beat: Tensor Decomposition for Monitoring Multi-person Breathing Beats With Commodity WIFI" ACM Transactions on Intelligent Systems and Technology, Vol.5, No.2, September 2017.

[4] Arman, University of Turku, "HICH: Hierarchical Fog-Assisted Computing Architecture for Healthcare IOT" ACM Transactions on Intelligent Systems and Technology, Vol.1, No.4, September 2017.

[5] Junk, Student Member, "A Wearable Gesture Recognition Device for Detecting Muscular Activities Based on Air-Pressure sensors" IEEE Transactions on Industrial Engineering, Vol.5, No.8, April 2016.

[6] Adam B. Noel, "Structural Health Monitoring Using Wireless Sensor Network", IEEE Transactions On Biomedical Engineering, Vol.17, No.3, February 2017.

[7] Ravi Kiran, "System Architecture For Low Power Ubiquitously Connected Remote Health Monitoring Applications With Smart Transmission Mechanism" IEEE Transactions On Sensors, Vol.15, No.8, August 2015.

[8] Gopi, "BSN-Care: A Secure IOT Based Modern HealthCare System Using Body Sensor Network" IEEE Transactions On Sensors Vol.6, No.5, March 2016.

[9] Cheng Yang, "Estimating Heart rate and Rhythm via 3D Motion Tracking in Depth video" IEEE Transactions on Multimedia, Vol.9, No.7, July 2017.

[10] Bharath Waj, "Impulse Radio Ultra-Wide band Communications For Localization and Tracking of Human Body and Limbs Movement for Healthcare Applications" IEEE Transactions On Antennas and Propagation, Vol.65, No.12, December 2017.

[11] Hamjisa, "Design and implementation of an Accurate, Portable and Time - Efficient Impatient - Based Transceiver for Structural Health Monitoring" IEEE Transactions on Mechatronics, Vol.2, No.6, December 2017.

[12] Woo Kim, "Heart Rate Detection During Sleep Using a Flexible RF Resonator and Injection - Locked PLL Sensor" IEEE Transactions On Biomedical Engineering, Vol.62, No.11, November 2015.

[13] Lin, "A Non Contact and Cost- Effective Sleep Monitoring System" IEEE Transactions On Biomedical Circuits And Systems, Vol.4, No.1, February 2017. 